\title{
Synergetic power optimization control of photovoltaic systems
}

\author{
Hadjira ATTOUI \\ QUERE Laboratory, Faculty of technology \\ University of Setif 1, Setif, Algeria \\ Farid KHABER \\ QUERE Laboratory, Faculty of technology \\ University of Setif 1, Setif, Algeria \\ Hamimi CHEMALI \\ Department of ELECTRONICS, Faculty of technology \\ University of Setif 1, Setif, Algeria
}

\begin{abstract}
A synergetic control (SC) technique is applied to develop a new maximum power point tracking (MPPT) control strategy for stand-alone photovoltaic (PV) systems through measuring PV array outputs and changing DC/DC converter control signal's duty cycle. The closed loop system stability is guaranteed using Lyapunov's method. This control strategy is simple and robust to irradiance and temperature variations. Simulation results are compared to those obtained using Hill Climbing method and then served to test the control robustness of the developed system. High performances under environmental parameter variations have demonstrated synergetic control usefulness.
\end{abstract}

Keywords - Synergetic control, Maximum power point tracking, Photovoltaic system, DC/DC converter, Hill Climbing, Stability.

\section{INTRODUCTION}

In recent years, the dramatic environmental issues associated to the huge fossil fuel uses and its severe consequences on cost and energy security are the main driving force behind the extra interest in PV system's alternatives. In fact, solar is not only reliable but easily available into two different forms, as heat energy in solar thermal collectors and in light in solar PV cells for electricity generation. For PV applications, MPPT is implemented since there is a mismatch between the load characteristics and the PV array maximum power points. The changes are related to both solar insolation and cell temperature. The most commonly control techniques are Hill-Climbing, Perturb and Observe (P\&O), Incremental Conductance (Inc-Cond), fractional open-circuit voltage $\left(\mathrm{V}_{\mathrm{oc}}\right)$, fractional short-circuit current control $\left(1_{\mathrm{sc}}\right)$ [1-5], intelligent methods as artificial neural networks $(\mathrm{NN})$, genetic algorithms and fuzzy logic (FL) [6-9]. For more details on these methods and related applications on solar energy, PV panel, the readers can refer to [8-14] and the references therein. The MPPT general requirements are simplicity and low cost, quick tracking under changing conditions, and mainly small output power fluctuation. Thus an efficient monitoring technique, which reduces these constraints and leads easily to get optimal resources, is highly recommended.

Recall that synergetic control (SC) theory was introduced in general terms by Koleskinov [15]. Its application to a single boost converter was introduced in [16], and some practical aspects with reference to both simulations and actual hardware were discussed in [17], and [18-19].

In this paper, a synergetic control is applied to track maximum power of photovoltaic system. Several advantages are in concern: higher precision, better stability, more simplicity and robustness. 
We firstly present, in this paper, the studied system coupled to the proposed MPPT. Then the modelisation of the overall system is developed. Finally obtained simulation results are presented to validate the synergetic control performances in comparison to the Hill climbing method.

\section{DESCRIPTION OF THE PROPOSED SYSTEM}

The configuration of the studied system is shown in Figure 1. It consists of a PV array, DC/DC boost converter, synergetic controller, and an output load.

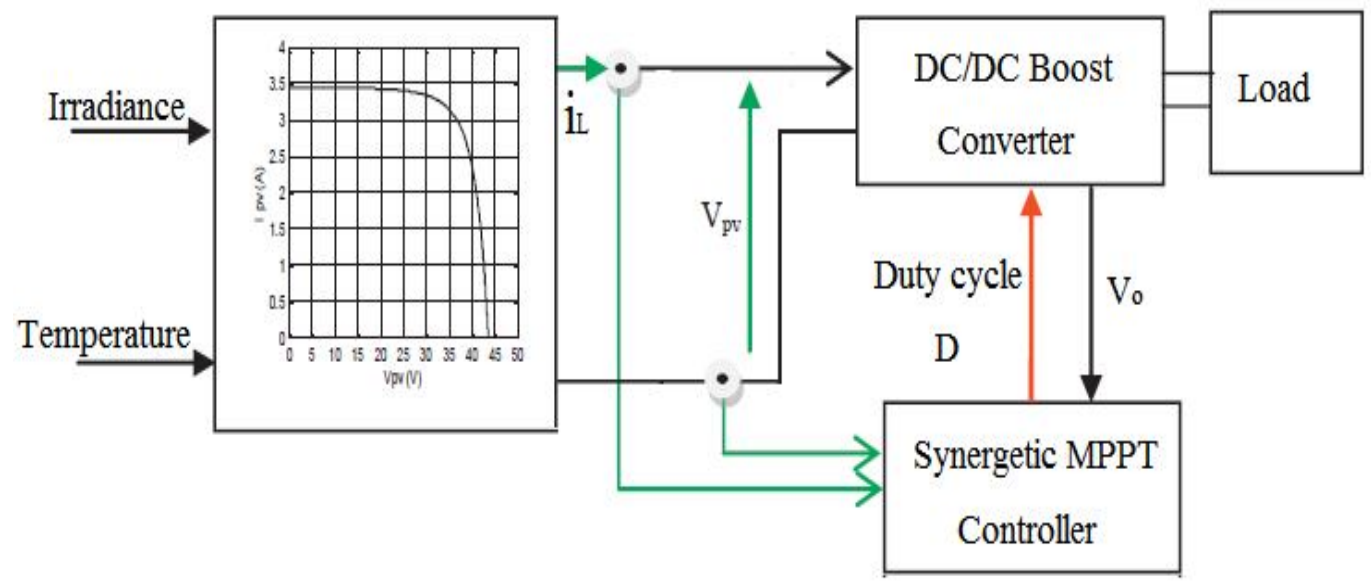

Figure 1. Proposed schematic system

\section{MODELING OF THE SYNERGETIC PROPOSED SYSTEM}

\section{A. The PV array model-}

$\mathrm{PV}$ array is a p-n junction semiconductor, which converts light into electricity. When the incoming solar energy exceeds the band-gap energy of the module, photons are absorbed by materials to generate electricity. The equivalentcircuit model of PV is shown in Figure 2.

It consists of a light-generated source, diode, series and parallel resistances.

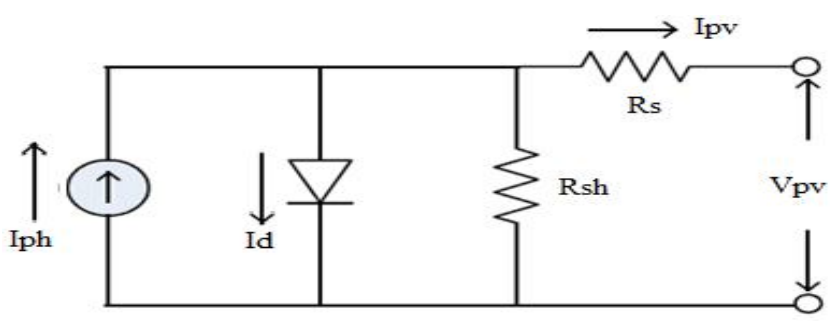

Figure 2. Solar cell's equivalent circuit

The present simulation is based on SP75 photovoltaic module datasheet. This module comprises 36 solar cells connected in series in order to produce a maximum output power of $75 \mathrm{~W}$ at $17 \mathrm{~V}$.

The parameters of this solar module are given in Table 1.

Table -1 PV panel SP75 Parameters 


\begin{tabular}{|c|c|}
\hline Parameter & Value \\
\hline & \\
Maximum output power $\mathbf{P}_{\text {max }}$ & $75 \mathrm{~W}$ \\
Open circuit voltage $\mathbf{V}_{\text {oc }}$ & $21.7(\mathrm{~V})$ \\
Short circuit current $\mathbf{I}_{\text {scr }}$ & $4.8(\mathrm{~A})$ \\
Rated current $\mathbf{I}_{\mathrm{MPP}}$ & $4.4(\mathrm{~A})$ \\
Rated voltage $\mathbf{V}_{\mathrm{MPP}}$ & $17(\mathrm{~V})$ \\
Temp. coefficient: short-circuit current $\mathbf{K}_{\mathrm{i}}$ & $2.06\left(\mathrm{~mA} /{ }^{\circ} \mathrm{C}\right)$ \\
\hline
\end{tabular}

Figure 3 shows obtained experimental and simulation electrical characteristics P-U and I-U on SP75 panel.
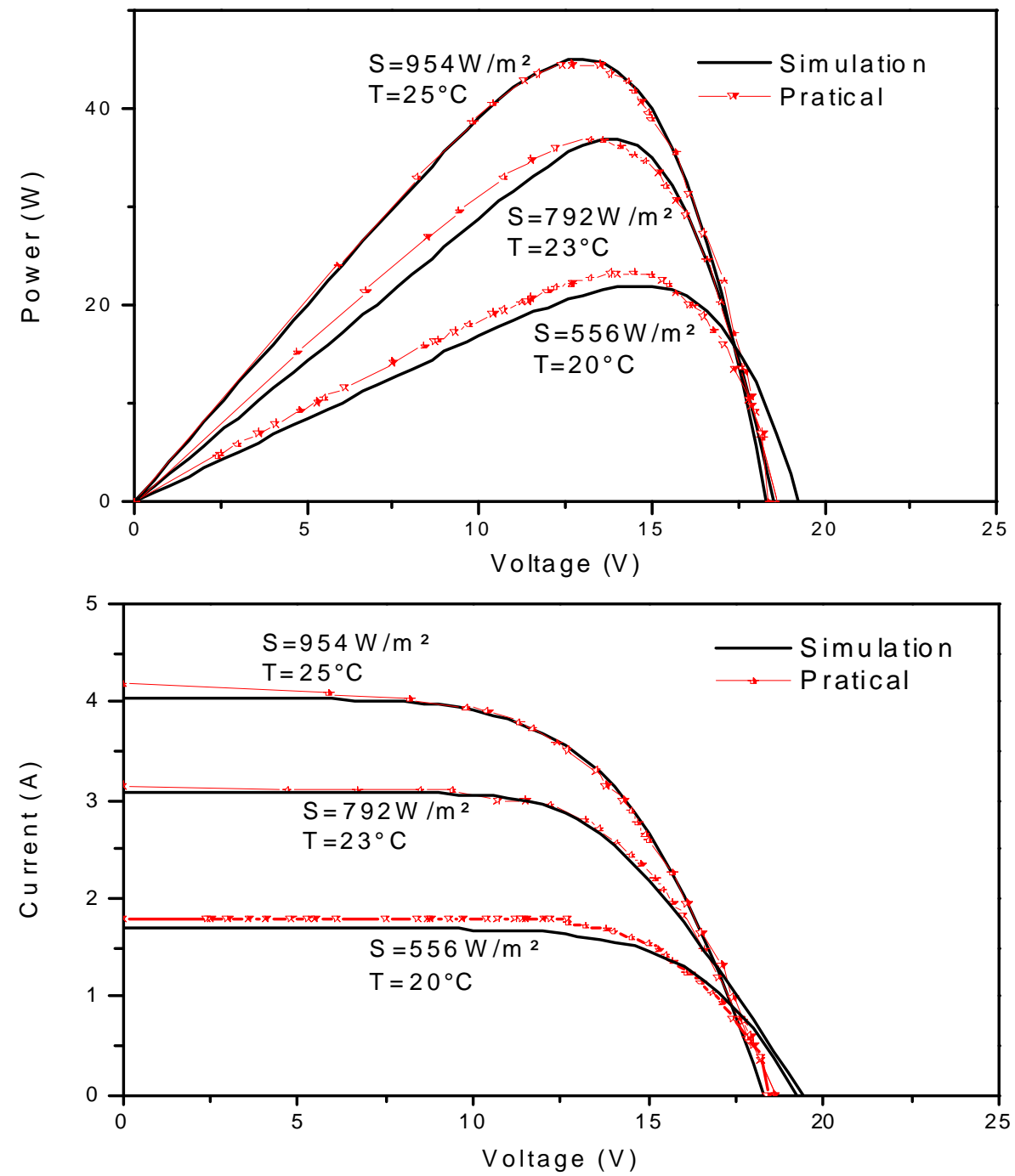

Figure 3. Comparison of experimental and simulation results: (a) Ppv $=f(U p v)$ and (b) $I p v=f(U p v)$ 


\section{B. MPPT Control strategy-}

\section{i. Hill Climbing}

Hill climbing involves a perturbation in the duty ratio of the power converter. In the case of a PV array connected to a power converter, perturbing the duty ratio of power converter perturbs the PV array current and consequently perturbs the PV array voltage. From Figure 4, it can be seen that incrementing (decrementing) the voltage increases (decreases) the power when operating on the left of the MPP and decreases (increases) the power when operating on the right of the MPP. Therefore, if there is an increase in power, the subsequent perturbation should be kept the same in order to reach the MPP and if there is a decrease in power, the perturbation should then be reversed.

The process is periodically repeated until the MPP is reached. The system then oscillates around the MPP. The oscillation can be minimized by reducing the perturbation step size. However, a smaller perturbation size will slow down the MPPT. So a solution to this conflicting situation is to dispose of a variable perturbation size that gets smaller towards the MPP [20-21].

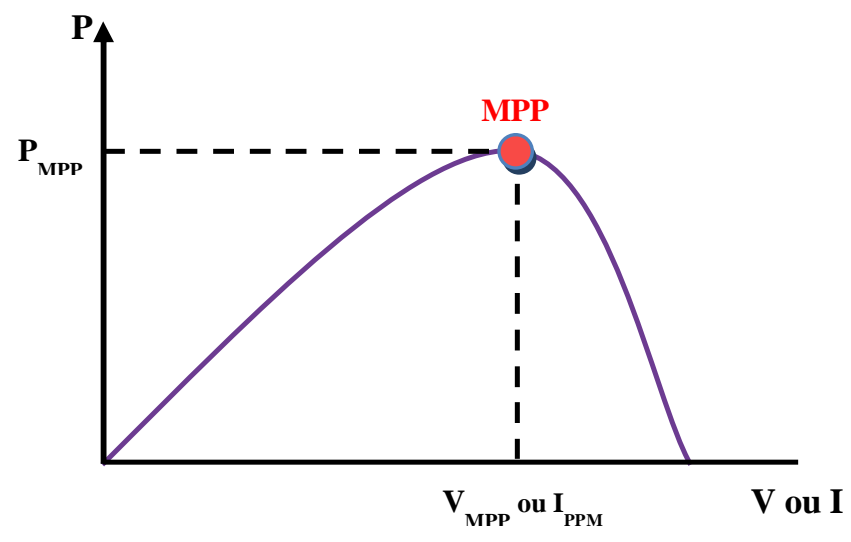

Figure 4. PV array power characteristic

\section{ii. Synergetic control}

The general synergetic procedure is revisited in this section [16].

The main steps of this synergetic procedure are summarized as follows.

Suppose the system to be controlled is described by a set of non linear differential equation of the form

$$
\frac{d x}{d t}=f(x, D, t)
$$

where $\mathrm{x}$ is the state variable vector, $\mathrm{D}$ is the control input vector and $\mathrm{t}$ is time.

Start by defining a macro-variable as a function of the state variables:

$$
\Psi=\Psi(x, t)
$$

The control signal will force the system to operate on the manifold

$$
\Psi=0
$$

The designer selects then the macro-variable characteristics according to the control specifications (e.g: limitation in the control output, the settling time, and so on). In the trivial case, the macro-variable is a simple state variable combination. This latter process is repeated to define as many macro-variables as control channels numbers. The desired dynamic evolution of the macro-variable is:

$$
T_{S}\left(\frac{d \Psi}{d t}\right)+\Psi=0 ; \quad T_{s}>0
$$


where $T_{S}$ is design parameter specifying the convergence speed to the manifold specified by the macro-variable equals to zero.

Differentiating the macro-variable $\Psi$ (2) along of (1) leads to :

$$
d \Psi / d t=(d \Psi / d x)(d x / d t)
$$

Combining (1), (4), and (5) we obtain

$$
T_{S}(d \Psi / d x) f(x, D, t)+\Psi=0
$$

Equation (6) finally serves to synthesize the control law D.

Upon solving Eq. (6) for D, the derived control law is expressed as:

$$
D=g\left(x, t, \Psi(x, t), T_{S}\right)
$$

From Equation (7), the control output depends not only on system variables but also on selected macro-variable and time constant $\mathrm{T}_{\mathrm{s}}$. The designer may choose the controller characteristic through selecting a suitable macro-variable and time constant $\mathrm{T}_{\mathrm{s}}$.

\section{SYNERGETIC CONTROL TRACKING OF PHOTOVOLTAIC SYSTEM}

In this work, the concept of the synergetic MPPT control is introduced (Figure 5):

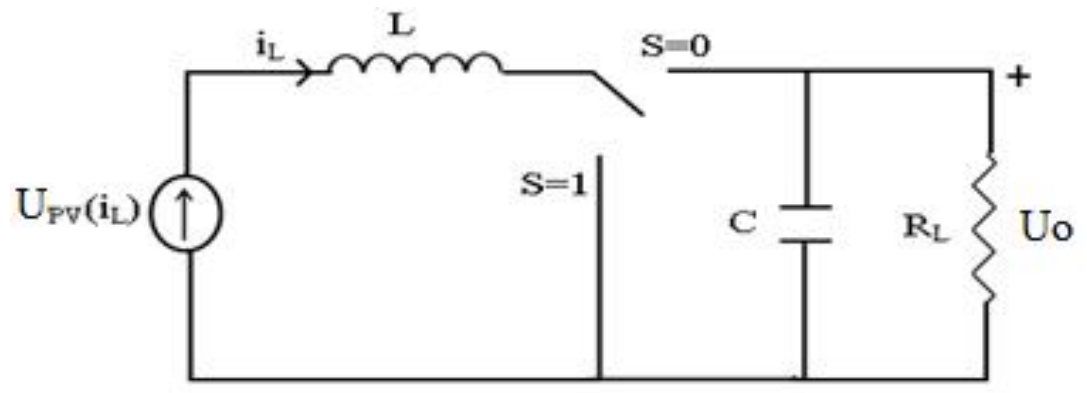

Figure 5. MPPT system circuit

The system is written as two state sets equation depending on the switch position.

$\frac{d i_{L}}{d t}=-(1-D) \frac{U_{o}}{L}+\frac{U_{p v}}{L}$

$\frac{d U_{o}}{d t}=(1-D) \frac{i_{L}}{C}-\frac{U_{0}}{R_{L} C}$

where $C$ is the capacity, $L$ is the inductance, $R_{L}$ is the resistive load, $D$ is the duty ratio control input $\in\left[\begin{array}{ll}0 & 1\end{array}\right]$. $U_{o}$ is the output voltage and $i_{L}$ is the inductor current. Note that the equivalent series resistance (ESR) of the inductor and wiring resistance are neglected in this case, so $i_{L}$ is assumed equal to the PV current $\left(\mathrm{I}_{\mathrm{PV}}\right)$. Eq. (8) is written in nonlinear time invariant system general form.

$\bar{x}=f(x)+g(x) D$

By selecting the manifold as $\partial \mathrm{P}_{\mathrm{PV}} / \partial \mathrm{I}_{\mathrm{PV}}=0$, it is guaranteed that the system state will hit the manifold and produce maximum power output persistently.

$$
\frac{\partial_{p v}}{I_{p v}}=\frac{a_{p v}^{2} R_{p v}}{\partial_{p v}}=2 I_{p v} R_{p v}+I_{p v}^{2} \frac{\sigma_{p v}}{\partial I_{p v}}=I_{p v}\left(2 R_{p v}+I_{p v} \frac{\mathscr{R}_{p v}}{d_{p v}}\right)=0
$$

where $\mathrm{Rpv}=\mathrm{V}_{\mathrm{PV}} / \mathrm{I}_{\mathrm{PV}}$ is the equivalent load connect to the PV, and $\mathrm{I}_{\mathrm{pv}}$ the $\mathrm{PV}$ current which is equal to $\mathrm{i}_{\mathrm{L}}$ in this case. 
The solution of (10) is $2 R_{p v}+I_{p v} \frac{d_{p v}}{\delta_{p w}}=0$.

Hence, the manifold is defined as:

$$
\Psi=2 R_{p v}+I_{p v} \frac{d R_{p v}}{a_{p v}}
$$

Then the desired dynamic evolution of the macro-variable is expressed as:

$$
\begin{array}{ll}
T_{S}(d \Psi / d x)+\Psi=0 ; & T_{S}>0 \\
\text { where } & \\
d \Psi / d t=(d \Psi / d x)(d x / d t) &
\end{array}
$$

The substitution of $\Psi^{\prime}$ from Eq. (13) into the functional equation (12) yields to

$T_{s}\left[\left(d \Psi / d x_{1}\right)(f(x)+g(x) D(t))\right]+\Psi=0$

$$
\left(\partial \Psi / \partial x_{1}\right)\left(\left(U_{p}-U_{0}\right) / L+\left(U_{0} / L\right) D(t)\right)=-\Psi / T_{z}
$$

$$
D(t)=1-\left(\psi_{L /}\left(U_{0} T_{s} \frac{\partial \Psi}{\partial x_{1}}\right)\right)-\left(\frac{U_{p v}}{U_{0}}\right)
$$

The time derivative of $\Psi\left(\frac{d \psi}{\hat{w}_{1}}\right)$ is then written in [22]:

The synergetic control signal is defined as:

$$
D(t)=1-\frac{\psi_{L}}{U_{o} T_{s}\left(\frac{3 \partial R_{p v}}{\partial i_{L}}+i_{L} \frac{\partial^{2} R_{p v}}{\partial i_{L}^{2}}\right)}-\frac{U_{p v}}{U_{o}}
$$

Asymptotic stability is obtained using the Lyapounov function candidate:

$$
V_{L}=\frac{1}{2} \psi^{2}
$$

The derivate of VL is:

Consequently we have:

$$
\frac{d V_{L}}{d t}=\psi\left(\frac{d \Psi}{d t}\right)=\Psi\left[\left(-\frac{1}{T_{g}}\right) \psi\right]
$$

$$
\frac{d V_{L}}{d t}=\left(-\frac{1}{T_{g}}\right) \Psi^{2} \leq 0
$$

\section{RESULT AND DISCUSIONS}

In this section, the simulation results of the studied system are presented.

The obtained results of the synergetic control approach are compared to Hill Climbing values in order to test its robustness.

The MPPT system specification used in the simulation is tabulated in Table 2. 
Table -2 System specifications

\begin{tabular}{|c|c|c|c|}
\hline Parameter & Value & Parameter & Value \\
\hline & $220(u F)$ & $\mathbf{R}_{\mathrm{L}}$ & $23 \Omega$ \\
$C$ & $440(m H)$ & $q$ & $1.6 \times 10^{-19}(C)$ \\
$L$ & 0.003 & $E_{g}$ & $1.12(e V)$ \\
$T_{s}$ & $298(K)$ & $k_{b}$ & $1.38 \times 10^{-23}(J / K)$ \\
$T_{r}$ & & &
\end{tabular}

To show the effectiveness of the proposed control algorithm, the PV system is modeled and simulated using Matlab/Simulink environment.

For all the simulation results in the [22], the synergetic control approach is able to maintain the output at optimum point and provides high robustness to external conditions variations.

Now the proposed and the Hill Climbing controllers are compared for irradiance change from $700 \mathrm{~W} / \mathrm{m}^{2}$ to 1000 $\mathrm{W} / \mathrm{m}^{2}$ during 0.9 seconds while the temperature is kept constant and equal to $25^{\circ} \mathrm{C}$ as illustrated in figure 6 and 7 .

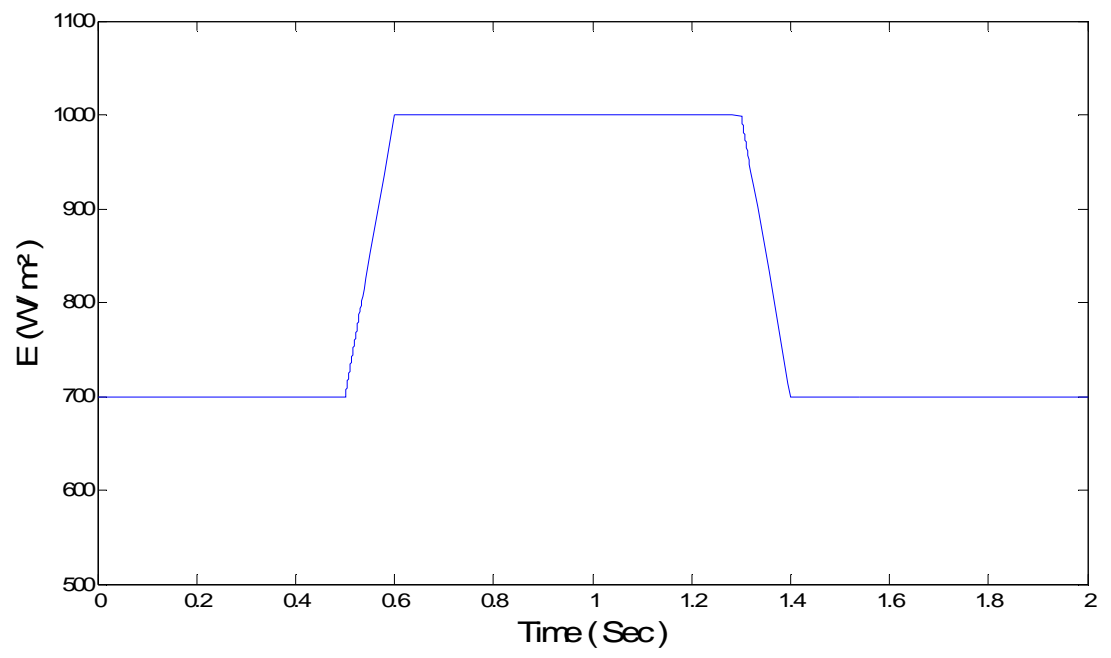

Figure 6. Irradiance's variation 


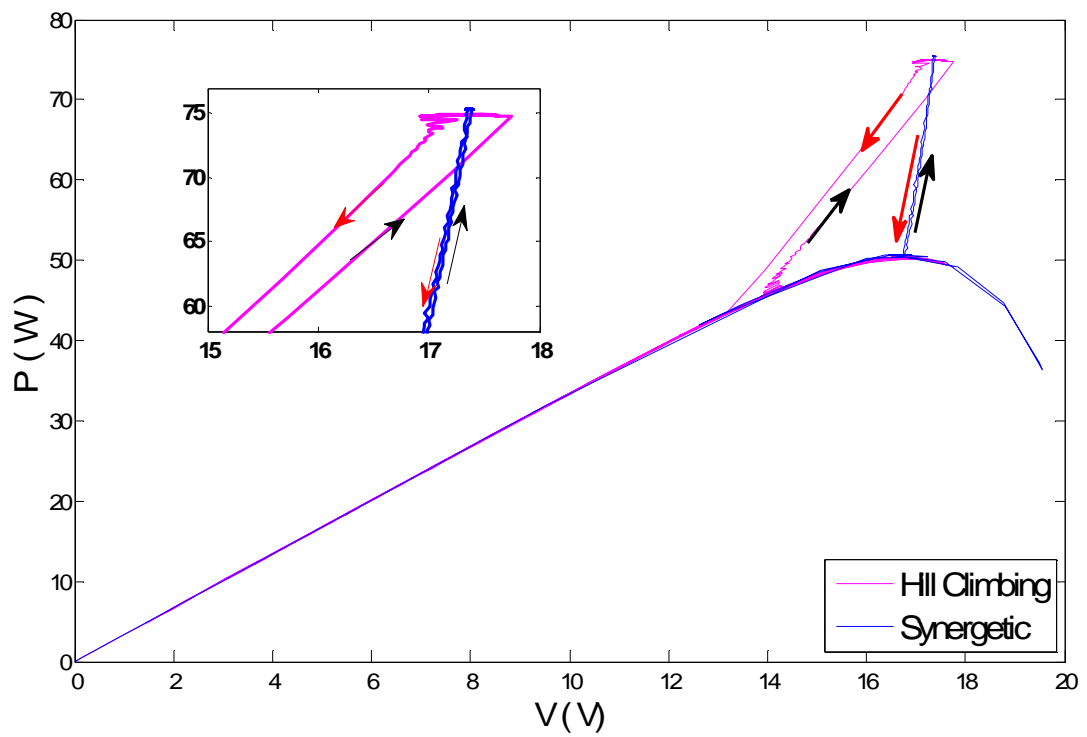

Figure 7. Output power versus voltage using Synergetic and Hill Climbing during variation's irradiance

Figures 8 and 9 show the P-V characteristic of the two controllers behavior in the case of temperature variation from $20^{\circ} \mathrm{C}$ to $50^{\circ} \mathrm{C}$.

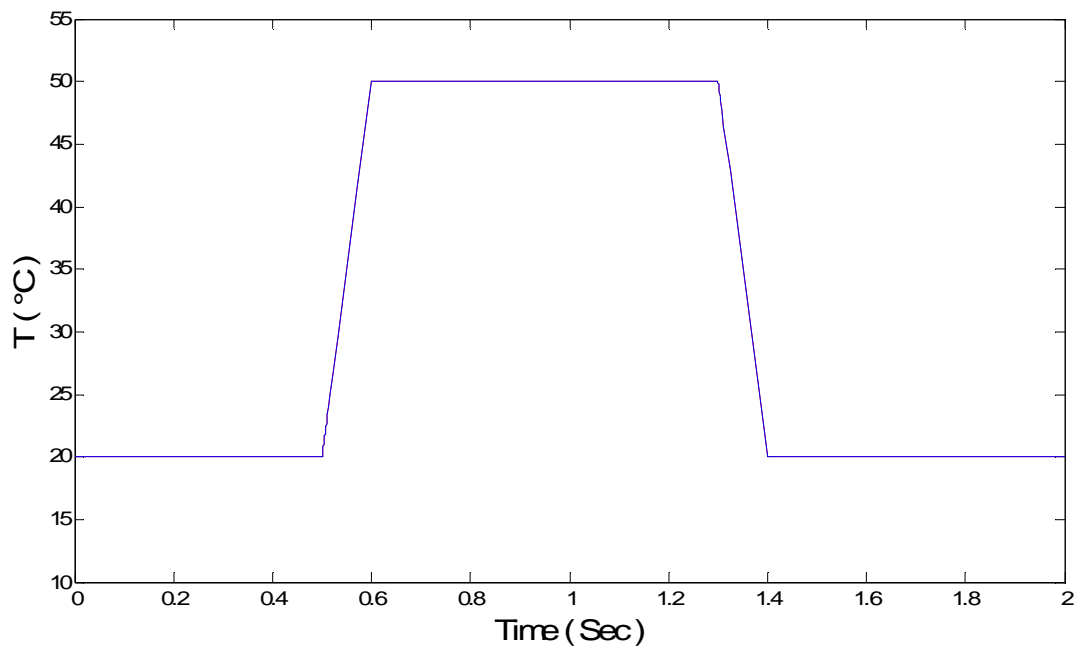

Figure 8. Temperature's variation 


\section{International Journal of Innovations in Engineering and Technology (IJIET) \\ http://dx.doi.org/10.21172/ijiet.83.030}

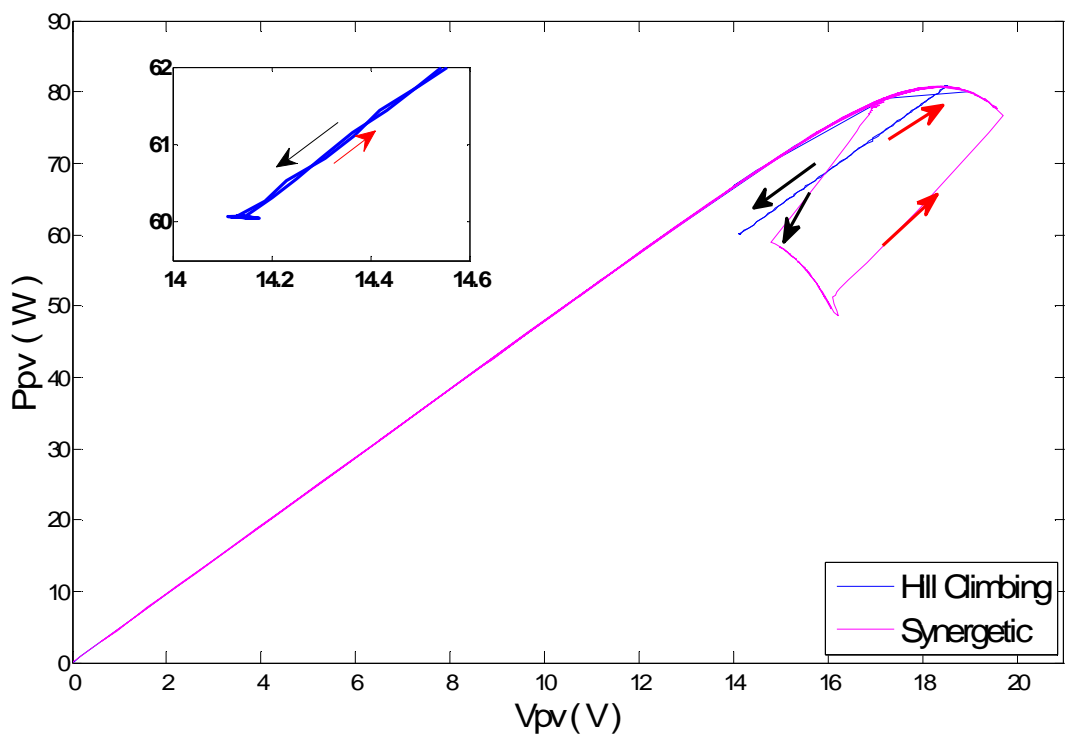

Figure 9. Output power versus voltage using Synergetic and Hill Climbing during variation's temperature

Obtained results show a good stability in steady state and a better efficiency compared to that of the Hill Climbing control. The study of robustness for both controllers showed that synergetic controller reach the MPP faster (the response time of the Synergetic Control is 0.006 and the Hill climbing is 0.04) than Hill climbing one in the case of irradiance and temperature variation.

\section{VI.CONCLUSION}

In this paper an efficient MPPT control strategy based on the synergetic control theory has been developed. The proposed controller has successfully tracked the maximum power point photovoltaic systems under different temperatures and solar irradiances. In Matlab/ Simulink simulation, extensive carried out tests have permitted to ensure the stability of the system and its robustness. In fact, the obtained results have showed an improvement in comparison to Hill climbing technique.

The considered synergetic control approach, since analytically simple and easily to build will certainly find track in multitude applications in the near future.

\section{REFERENCE}

[1] M. A. S. Masoum, H. Dehbonei, and E. F. Fuchs, Theoretical and experimental analyses of photovoltaic systems with voltage- and currentbased maximum power-point tracking, IEEE Trans. Energy Convers., vol. 17, no. 4, pp.514-522, Dec. 2002.

[2] T. Esram, and P. L. Chapman, Comparison of photovoltaic array maximum power point tracking techniques, IEEE Trans. Energy Convers., vol. 22, no. 2, pp. 439-449, Jun. 2007.

[3] N. Femia, G. Petrone, G. Spagnuolo, and M. Vitelli, Optimization of perturb and observe maximum power point tracking method, IEEE Trans. Power Electron., vol20, no. 4, pp. 963-973, Jul. 2005

[4] E. Koutroulis, K. Kalaitzakis, and N. C. Voulgaris, Development of a microcontroller-based, photovoltaic maximum power point tracking control system, IEEE Trans. Power Electron., vol.16, no. 1, pp. 46-54, Jan. 2001.

[5] K. H. Hussein, I. Muta, T. Hoshino, and M. Osakada, Maximum photovoltaic power tracking: an algorithm for rapidly changing atmospheric conditions, in IEE Proc. Generation, Transmission and Distribution, vol. 142, 1995, pp. 59-64. 


\section{International Journal of Innovations in Engineering and Technology (IJIET) \\ http://dx.doi.org/10.21172/ijiet.83.030}

[6] N. Khaehintung, A. Kunakorn, and P. Sirisuk, A Novel Fuzzy Logic Control Technique tuned by Particle Swarm Optimization for Maximum Power Point Tracking for a Photovoltaic System using a Current-mode Boost Converter with Bifurcation Control, International Journal of Control, Automation, and Systems (2010) 8(2):289-300.

[7] S. Kim, Robust maximum power point tracker using sliding mode controller for the three-phase grid-connected photovoltaic system, Solar Energy 81 (2007) 405-414.

[8] H. Chih-Lyang, C. Li-Jui, Y. Yuan-Sheng, Network-based fuzzy decentralized sliding-mode control for car-like mobile robots, IEEE Transactions on Industrial Electronics 54 (2007) 574-585.

[9] T.A. Venelinov, C.G. Leonardo, G. Vincenzo, C. Francesco, K. Okyay, Sliding mode neuro-adaptive control of electric drives, IEEE Transactions on Industrial Electronics 54 (2007) 671-679.

[10] Ch. Ben Salah, M. Chaaben, M. Ben Ammar, Multi-criteria fuzzy algorithm for energy management of a domestic photovoltaic panel, Renewable Energy 33 (2008) 993-1001.

[11] S.A. Kalogirou, Artificial neural networks in renewable energy systems applications: a review, Renewable and Sustainable Energy Reviews 5 (2001) 373-401.

[12] B. Leger, J.B. Lopez-Velasco, J.M. Emidio, Thermal flux characterization of multi-holed plates using neural networks: application to combustion chamber walls, International Journal of Thermal Sciences 41 (2002) 1089-1100.

[13] F. Moutarde, Introduction aux réseaux de neurones, Ecole des Mines de Paris Avril, 2007.

[14] Ouldcherchali. N, Morsli. A,Boucherit.M. S,Barazane. L, Robust Controller to Extract the Maximum Power of a Photovoltaic System, Journal of Electrical \& Electronics Engineering; May 2014, Vol. 7 Issue 1, p117.

[15] A. Kolesnikov et al., Modern Applied Control Theory: Synergetic Approach in Control Theory (in Russia). Moscow: TSURE Press, 2000, vol. 2.

[16] A. Kolesnikov, G. Veselov, A. Monti, F. Ponci, E. Santi, and R. Dougal, Synergetic synthesis of DC-DC boost converter controllers: Theory and experimental analysis, in Proc. 17th Annual IEEE Applied Power Electronics Conf., vol. 1, Dallas, TX, Apr. 2002, pp. 409415.

[17] E. Santi, A. Monti, D. Li, K. Proddutur, and R. Dougal, Synergetic control for DC-DC boost converter: Implementation options, in Proc. 37th IEEE Industry Applications Society Annual Meeting, vol. 2, Oct. 2002, pp. 13-18.

[18] D. Li, K. Proddutur, E. Santi, and A. Monti, "Synergetic control of a boost converter: Theory and experimental verification," in Proc. IEEE Southeast Conf., Apr. 2002, pp. 197-200.

[19] A. Mechter, K. Kemih, M. Ghanes, Sliding Mode Control of a Wind Turbine with Exponential Reaching Law, Acta Polytechnica Hungarica, Vol. 12, No. 3, 2015,pp. 167-183.

[20] Trishan Esram, Patrick L. Chapman, Comparison of Photovoltaic Array Maximum Power Point Tracking Techniques, IEEE Transactions On Energy Conversion, June 2007.

[21] W. Xiao and W. O. Dunford, A modified adaptive hill climbing MPPT method for photovoltaic power systems," in Proc. 35th Annual IEEE Power Electron. Spec. Conf., 2004, pp. 1957-1963.

[22] H. Attoui, F. Khaber, M. Melhaoui, K. Kassmi, N. Essounbouli, "Development and experimentation of a new MPPT synergetic control for photovoltaic systems," Journal of Optoelectronics and Advanced Materials, Vol.18, 2016, pp. 165-173. 